\title{
Desigualdade de Renda, Pobreza, Crescimento Econômico e Indústria no Brasil: Relações de Curto e Longo Prazos via Modelos ARDL
}

Patrick Leite Santos (IERI/UFU);

Carlos C. S. Saiani (IERI/UFU);

Michele Polline Veríssimo (IERI/UFU)

resumo:

Este estudo investiga relações de curto e longo prazos entre desigualdade de renda, pobreza, crescimento econômico e participação da indústria no emprego no Brasil com dados de 1980 a 2010. Para isso, são estimados modelos Autorregressivos de Defasagens Distribuídas (ARDL) com o objetivo de avaliar como a indústria afeta desigualdade e pobreza e testar três hipóteses tradicionais da literatura: Curva de Kuznets, economia dual e crescimento pró-pobre. As evidências sinalizam efeitos heterogêneos do crescimento e da indústria na pobreza e desigualdade no tempo, com redução dos problemas sociais pelo crescimento no longo prazo e pelo emprego industrial no curto prazo.

palavras-chave:

Desigualdade de Renda; Pobreza; Crescimento Econômico; Indústria; ARDL.

Código JEL:

014; 015; 047.

Área Temática:

1.4 Padrões de especialização produtiva e desenvolvimento. 


\section{Introdução}

A indústria é considerada pela literatura baseada em Kaldor (1968) como o "motor" do crescimento econômico; pela literatura derivada de Kuznets (1955), o setor que promove, ao longo do tempo, a redução da desigualdade de renda. Já Kakwani e Pernia (2000) defendem que o crescimento deve favorecer os mais pobres, sendo os setores econômicos um dos canais de transmissão, destacando-se o industrial. Ademais, tal setor tem dinâmica de inserção de valor agregado na produção que não é observada na mesma magnitude nos demais setores, resultando em maior produtividade relativa e maiores benefícios à sociedade. A transmissão pode ocorrer via geração direta de emprego, por elevação da demanda por bens e serviços oriundos de outros setores ou via oferta de produtos que aumentam a produtividade das pessoas (KALDOR, 1968).

Considerando tais argumentos, pode-se sugerir que a indústria seja capaz de dinamizar a economia e melhorar a distribuição de renda. Porém, vários países convivem com desigualdade, pobreza e desindustrialização. O Brasil é um exemplo. As dinâmicas da desigualdade de renda e da pobreza associadas ao crescimento econômico e à (des)industrialização sempre nortearam debates associados desde ao desenvolvimento brasileiro (FURTADO, 1967), passando pela concentração espacial da indústria e renda (CANO, 1981) e pelo caráter concentrador do crescimento impulsionado pela industrialização no "milagre econômico" (GANDRA, 2005).

Em períodos mais recentes, os debates para o Brasil focam a queda da desigualdade e da pobreza na década de 2000 (BARROS et al., 2006), mas permanecendo o país em uma situação relativamente pior a de outros similares (VEGH et al., 2019), e a possível desindustrialização, sem enfatizarem a interdependência destes fenômenos. Mais especificamente, há uma lacuna ainda pouco explorada na literatura nacional acerca dos impactos de curto e longo prazos do crescimento econômico e da (des)industrialização na desigualdade de renda e, principalmente, na pobreza. Nesse contexto, o objetivo deste estudo é investigar efeitos de curto e longo prazos da indústria e do crescimento sobre indicadores brasileiros de desigualdade de renda e pobreza.

Para isso, são estimados Modelos Autorregressivos de Defasagens Distribuídas (ARDL) aplicados à cointegração (PESARAN; SHIN, 1999; PESARAN et al., 2001). A principal vantagem deste método é justamente possibilitar a avaliação de relações de curto e longo prazos entre as variáveis consideradas. As estimações utilizam dados anuais brasileiros das décadas de 1980 a 2010 - a maior série para a qual todas as informações necessárias estão disponíveis. As fontes dos dados são: Banco Mundial, Instituto de Pesquisa em Economia Aplicada (IPEA), Pesquisa Nacional por Amostra de Domicílios (PNAD) do Instituto Brasileiro de Geografia e Estatística (IBGE) e Relação Anual de Informações Sociais (RAIS) do Ministério da Economia.

Além de avaliar se a indústria afeta a desigualdade de renda e a pobreza e se os possíveis efeitos são heterogêneos no tempo, este estudo testa três hipóteses tradicionais da literatura: i) a hipótese associada à discussão da Curva de Kuznets de que o crescimento econômico elevaria a desigualdade de renda no curto prazo e a reduziria no longo prazo, sendo a dinâmica da indústria uma de suas potenciais explicações - pela ii) hipótese da economia dual (KUZNETS, 1955) -; e iii) a hipótese da possibilidade de crescimento econômico pró-pobre - aquele que, necessariamente, beneficia os mais pobres, reduzindo a pobreza (RAVALLION; CHEN, 2003).

Para testar as hipóteses e cumprir seu objetivo, o presente estudo possui mais três seções, além desta introdução e das considerações finais. Na segunda, é realizada uma breve revisão da literatura (teórica e empírica) para fundamentar as hipóteses testadas e opções das estratégias empíricas. Na terceira, são discutidos os procedimentos metodológicos baseados em modelos ARDL e os dados. Na quarta, os resultados das estimações são apresentados e analisados.

Antecipadamente, vale apontar que os resultados encontrados não refutam a hipótese do efeito positivo do crescimento econômico na desigualdade de renda no curto prazo e negativo no longo prazo, o que está de acordo com a Curva de Kuznets. Já a hipótese do crescimento pró-pobre é corroborada apenas no longo prazo. Portanto, os efeitos do crescimento econômico sobre a desigualdade de renda e a pobreza são heterogêneos no tempo. O mesmo é observado para a indústria ( proxy participação industrial no emprego). Nesse caso, contudo, as relações são de curto prazo, assim como para políticas de valorização do salário mínimo e educacionais. 


\section{Embasamento teórico e empírico}

\subsection{Desigualdade, crescimento e indústria}

Kuznets (1955) mostra, com dados dos séculos XIX e XX dos Estados Unidos, Alemanha e Inglaterra, indícios de uma relação não linear, em formato próximo a um "U-invertido", entre a desigualdade de renda e o nível de renda per capita, sugerindo que, em baixos níveis de renda per capita, a desigualdade aumenta em função do crescimento econômico, mas passa a diminuir com o crescimento a partir de determinado nível (turning point). Dessa forma, o crescimento seria, inicialmente, concentrador de renda, mas criaria ao longo do tempo as condições para a reversão da concentração. Esta hipótese ficou conhecida como Curva de Kuznets (CK).

Vários trabalhos investigam tal hipótese, alguns apenas a testando e a apresentando como um fato estilizado, enquanto outros também se preocupam em sinalizar possíveis justificativas. Há surveys que sintetizam as principais justificativas apontadas pela literatura. Dentre estes, Deutsch e Silber (2000) as divide, segundo as abordagens base, em: i) crescimento endógeno (New Growth); ii) Teoria da Escolha Pública (Public Choice); e iii) economia dual. O segundo e, principalmente, o terceiro grupos são os mais alinhados à discussão do presente estudo, pois ressaltam o papel da dinâmica setorial e, mais especificamente, da indústria.

No primeiro grupo, simplificadamente, argumenta-se que, com baixos níveis de renda, as economias apresentam mercados de crédito imperfeitos e distribuições desiguais do capital humano e, consequentemente, da renda. Tais características são condições necessárias para o investimento em capital humano, inicialmente concentrado, e o crescimento econômico. No tempo, o crescimento reduz as imperfeições nos mercados de créditos e gera transbordamento de conhecimento para os pobres (trickle-down), que passam a obter melhores remunerações e, assim, a desigualdade diminui (GALOR; TSIDDON, 1996; DAHAN; TSIDDON, 1998).

Os argumentos associados à Teoria da Escolha Pública fundamentam-se nas interações entre mecanismos políticos e estrutura econômica. Alguns trabalhos consideram a participação política como exógena; outros como endógena. Nos primeiros, a CK é explicada pelo efeito tributário regressivo, que eleva a desigualdade em níveis baixos de renda; porém, a consequente arrecadação, se revertida em políticas redistributivas e investimentos em capital humano, reduz a desigualdade. A CK também decorreria de heterogeneidades da população e da capacidade desta de exercer controle social (ALESINA; RODRIK, 1994; ALESINA; GLAESER, 2004).

Com participação política endógena, defende-se que esta é afetada pela educação. Em baixos níveis de renda, apenas uma pequena parte da população consegue investir em capital humano e, assim, influenciar o processo político (controle social), empreendendo pouco esforço para adoção de políticas redistributivas. Conforme a economia cresce, mais pessoas acumulam capital humano e participam do processo político, aumentando a demanda por tais políticas e, possivelmente, as suas adoções, considerando que os governantes tendem a ser motivados por oportunidades eleitorais (GRADSTEIN; JUSTMAN, 1999; DEUTSCH; SILVER, 2001).

Ainda na abordagem da Teoria da Escolha Pública, independentemente da participação política como endógena ou exógena, o efeito da indústria na distribuição de renda se daria via políticas redistributivas. Argumenta-se que tais políticas tendem a ser mais adotadas à medida que aumenta a urbanização, que é atrelada ao avanço da participação da indústria na economia. Quanto maior a urbanização, maior a proximidade entre os indivíduos e, assim, maiores suas capacidades de organização e pressão sobre governantes para o atendimento de suas demandas. A maior organização também pode levar a um maior poder de barganha para os trabalhadores em negociações salariais, afetando a desigualdade de renda (GRADSTEIN; JUSTMAN, 1999).

No terceiro grupo, o papel da indústria é mais direto, tendo sido utilizado, inclusive, por Kuznets (1955). $\mathrm{Na}$ abordagem dual, a migração de trabalhadores entre setores econômicos, do menos (tradicional) ao mais dinâmico (moderno), gera elevação inicial da desigualdade; porém, a consolidação do novo setor leva à queda da desigualdade. Defende-se que tal dinâmica ocorre na transição de uma economia baseada na agropecuária (rural) a uma industrial (urbana), sendo a explicação embasada no diferencial setorial de rendimentos. No início da industrialização, a produtividade marginal do trabalho - e, consequentemente, os rendimentos industriais cresce mais rapidamente, elevando a desigualdade. Porém, à medida que a indústria se consolida, com a migração de trabalhadores motivados pelo diferencial de salários, a desigualdade diminui.

Pelas evidências existentes, inclusive para o Brasil, não há consenso se a CK é sempre válida. Os resultados são sensíveis às opções empíricas, como às proxies de desigualdade e especificações (AHLUWALIA, 1976; ADELMAN; ROBINSON, 1989; ANAND; KANBUR, 1993; DEUTSCH; SILBER, 2001; PIKETTY, 2006; LINHARES et al., 2012). Ademais, alguns trabalhos, principalmente com dados mais recentes, advogam que a relação desigualdade-crescimento é cíclica. Nessa linha, destacam-se os trabalhos que 
defendem a relação em formato próximo a um "N". As possíveis justificativas a tal formato também passam pela abordagem dual - no caso, a transição da economia industrial para a baseada em serviços - e por questões tributárias, trabalhistas e redistributivas (LIST; GALLET, 1999; PIKETTY, 2006).

No Brasil, a hipótese da CK teve destaque na "controvérsia de 70", debate de algumas visões na tentativa de explicar o caráter concentrador de renda do crescimento impulsionado pela industrialização no período do "milagre econômico" brasileiro (1968 a 1979) no governo militar. Uma das visões associa sua explicação à Teoria do Capital Humano e à abordagem dual da CK - migração de trabalhadores do setor rural relativamente mais atrasado para a indústria (LANGONI, 1973). As explicações das outras vertentes baseiam-se em: políticas econômicas, dinâmica do salário mínimo e hierarquia e políticas salariais das empresas (GANDRA, 2005).

Em paralelo à "controvérsia de 70", outros trabalhos discutem o caráter concentrador do "milagre econômico", inclusive enfatizando o papel da industrialização. Nesse sentido, pode-se destacar a "escola de Campinas", para a qual a concentração já estava presente na estrutura produtiva brasileira, sendo que a industrialização somente aprofundou e escancarou o problema devido à forma pela qual ocorreu, priorizando atividades mais concentradoras de renda - por exemplo, os bens duráveis (MELLO, 1986; CARDOSO; POCHMANN, 2000).

Por último, vale apontar outras evidências para o Brasil. Primeiro, que a indústria tende a ser menos concentradora de renda que os outros setores econômicos (OLIVEIRA; SILVEIRA NETO, 2016). Com dados agregados para os estados, Linhares et al. (2012) mostram indícios de variabilidade do efeito da indústria na desigualdade de renda. Já Santos et al. (2018), com dados municipais, sinalizam uma relação não linear entre a desigualdade de rendimentos do trabalho e a industrialização, sugerindo que a desigualdade piora com a industrialização até determinado nível de participação industrial na economia, a partir do qual passa a melhorar. Assim, tal trabalho explora mais a supracitada abordagem dual que justifica a CK, avaliando como a composição setorial afeta a desigualdade de renda. Na literatura internacional também há evidências nesse sentido (RAVALLION; CHEN, 2007; CHRISTIAENSEN et al., 2010).

\subsection{Pobreza, crescimento e indústria}

A pobreza é um fenômeno complexo, existindo várias propostas de conceitos absolutos e relativos. A pobreza absoluta é definida a partir de um parâmetro considerado como o mínimo necessário a uma qualidade de vida aceitável. Medidas de "linha de pobreza" baseadas em uma renda mínima ou em calorias mínimas diárias são exemplos. Já a pobreza relativa é relacionada a quanto um indivíduo tem menos de um recurso comparativamente aos demais ou a grupos específicos. Nesse caso, a pobreza não significa, necessariamente, escassez ou impossibilidade de acesso a um recurso (CRESPO; GUROVITZ, 2002; KAGEYAMA; HOFFMANN, 2006).

Assim, a linha de conceituação relativa já sinaliza a relação entre pobreza e desigualdade. Ademais, mesmo na vertente absoluta, a literatura reconhece que desigualdade e pobreza são problemas sociais relacionados, em especial no Brasil (BARROS et al., 2001). Considerando tais aspectos, é possível inferir alguns efeitos na pobreza a partir das já mencionadas relações entre desigualdade de renda, crescimento econômico e indústria. Porém, como este estudo adota uma medida absoluta e, principalmente, há na literatura algumas discussões e evidências, cabe fazer comentários específicos para as possíveis relações entre pobreza, crescimento e indústria.

A relação mais difundida parte do pressuposto de que variações na pobreza deveriam ser inversamente relacionadas a variações do crescimento econômico. Ou seja, em momentos de grande crescimento, a pobreza reduziria, e o contrário ocorreria em momentos de estagnação ou decrescimento (RAVALLION; CHEN, 2003). Assim, o crescimento diminuiria a pobreza, problema social que gera efeitos negativos na sociedade, desde a questão do bem-estar, como é explorada por Sen (1992), até aspectos econômicos. Por outro lado, segundo Kakwani e Pernia (2000), a redução da pobreza também é uma condição para o crescimento, pois, pelo lado da demanda, representa parcela do consumo potencial de uma economia que é restringido; já pela oferta, uma subutilização do potencial produtivo da totalidade do fator trabalho disponível.

Uma crítica à defesa do crescimento como mecanismo de combate à pobreza é que nem sempre ele é pró-pobre - nem sempre beneficia os mais pobres (RIBEIRO et al., 2015). Primeiramente, por poder ser prórico. Além disso, baseando-se no potencial trade-off entre a eficiência econômica e a equidade, é possível argumentar que: i) o crescimento econômico (pró-pobre, pró-rico ou mais equitativo) pode ser economicamente ineficiente; ii) por outro lado, um crescimento tido como eficiente pode resultar em distúrbios que reduzem a equidade e elevam a pobreza; e iii) o crescimento (pró-pobre ou pró-rico) pode gerar distúrbios na eficiência e na equidade. Assim, nem sempre o crescimento reduz a pobreza (KAKWANI; PERNIA, 2000).

Deve-se destacar, ainda, que há duas vertentes de definição e mensuração do crescimento pró-pobre. 
Para uma, este é observado se a pobreza reduzir mais do que ocorreria na ausência de crescimento. Assim, os benefícios para os mais pobres devem ser superiores aos dos demais (KAKWANI; PERNIA, 2000; RAVALLION, 2004). Para a outra vertente, é necessariamente aquele seguido por redução da pobreza (RAVALLION, CHEN, 2003; RAVALLION, 2004). Alinhado à primeira, Kakwani e Pernia (2000), por exemplo, propõem a análise do crescimento pró-pobre decompondo a pobreza nas elasticidades renda-pobreza e crescimento-igualdade. Já alinhados à segunda vertente, Ravallion e Chen (2003) sugerem a análise da dinâmica da taxa de pobreza e Son (2004) propõe uma curva crescimento-pobreza baseada na Curva de Lorenz.

Nos trabalhos de crescimento pró-pobre, é comum o argumento de que a relação entre a pobreza e o crescimento é complexa, não trivial e com dinâmica distinta entre as economias, ressaltando a importância de exercícios empíricos - o que é feito neste estudo. Isto porque o impacto do crescimento na pobreza depende de diversos fatores que funcionam como canais de transmissão. Na literatura, argumenta-se que os setores produtivos, como o industrial, são canais de transmissão dos efeitos do crescimento aos indivíduos, principalmente via a geração de emprego e renda (KAKWANI; PERNIA, 2000; TOCHETTO et al., 2004; HICHEM, 2016).

$\mathrm{Na}$ concepção da transmissão pelo padrão setorial, a ideia é que o aumento da produção ocorre internamente aos setores. Contudo, a transmissão depende do efeito distribuição e da dinâmica gerada de forma direta pelo setor (sensibilidade da pobreza ao crescimento setorial), em especial pela abertura deste aos pobres, com geração de empregos, ou pela interdependência, provocando o aumento da demanda por produtos ou serviços de setores com maior abertura aos pobres ou via oferta de produtos que aumentam a produção destes (LIPTON; RAVALLION, 1995; THORBECKE; JUNG, 1996). Assim, considerando Kaldor (1968), é plausível supor que a indústria, por ter dinâmica de inserção de valor agregado na produção superior aos demais setores, resulta em maior produtividade relativa e maiores benefícios para toda a sociedade.

Porém, Thorbecke e Jung (1996), para a Indonésia, sinalizam que o aumento dos produtos da agricultura e dos serviços contribuem mais do que o industrial para a redução da pobreza. Já Datt e Ravallion (1998) investigam o efeito do crescimento da agricultura na pobreza rural na Índia, observando que o aumento da produtividade agrícola gera redução relativa e absoluta da pobreza nas famílias rurais. Tal efeito ocorre por dois canais: elevação da produtividade (ou acesso a mais trabalho) e aumento salarial (ou redução do preço dos produtos agrícolas). Além disso, devido à rigidez de salários e preços, o efeito do crescimento agrícola é maior no longo prazo. Especificamente para o Brasil, não foram encontrados trabalhos com efeitos setoriais na pobreza, mas há alguns que avaliam a relação entre pobreza e crescimento, embasados ou não pela literatura sobre a hipótese do crescimento pró-pobre (RIBEIRO et al., 2015; SILVA, 2016).

\section{Metodologia e dados}

A hipótese da CK é tradicionalmente testada com estimações econométricas em que a variável dependente é uma medida de desigualdade e a explicativa é a renda ou o produto per capita, sendo a última considerada como um polinômio de $2^{\circ}$ grau (função quadrática). Se o coeficiente da variável em nível for positivo e o coeficiente desta ao quadrado for negativo (significativos), o "U-invertido" é sinalizado. Já para testar a relação desigualdade-renda no formato próximo a um "N", a medida de renda/produto é empregada em um polinômio de $3^{\circ}$ grau (função cúbica). Se os coeficientes forem significativos, positivo em nível e ao cubo e negativo ao quadrado, a hipótese do "N" não é refutada. Um potencial problema destas estratégias empíricas é que os resultados podem ser enviesados por uma possível colinearidade ou multicolinearidade entre a renda/produto per capita em nível, ao quadrado e ao cubo.

Frente a tal problema, a literatura sugere como alternativa para testar a hipótese da CK a comparação dos efeitos do crescimento econômico na desigualdade de renda no curto e longo prazos. Para isso, com séries temporais, são sugeridas estimações por modelos Autorregressivos de Defasagens Distribuídas (ARDL) (JALIL, 2015). Se o efeito for positivo no curto e negativo ou positivo com menor magnitude no longo prazo, pode-se inferir que, primeiro, o crescimento econômico eleva a desigualdade, mas com o tempo a reduz, em consonância com a CK. Se os efeitos forem positivos nos dois períodos e maiores no longo prazo, a hipótese da CK é refutada, como seria na estratégia tradicional com uma relação desigualdade-crescimento em "N".

Em avaliações das relações entre desigualdade, pobreza e crescimento que exploram o papel da indústria, a literatura também sugere o emprego de modelos ARDL (HICHEM, 2016). Para ressaltar ainda mais a importância do método, é importante resgatar evidências da literatura já comentadas: i) a possível relação da CK é justificada pela abordagem dual justamente pela dinâmica da participação da indústria na economia (KUZNETS, 1955; DEUTSCH; SILVER, 2001); e ii) possibilidade de uma relação não linear entre a desigualdade e a industrialização (SANTOS et al., 2018). Considerando estas evidências, a potencial relação 
entre a desigualdade e a pobreza, em especial no Brasil (BARROS et al., 2001), e possíveis efeitos heterogêneos da industrialização na pobreza (RAVALLION, 1997; SON, 2004), cabe avaliar se a participação da indústria no emprego tem efeitos heterogêneos no tempo na desigualdade e a pobreza.

Assim, para investigar possíveis relações de curto e longo prazos entre desigualdade de renda, pobreza, crescimento econômico e participação industrial no emprego para o Brasil, são estimados modelos ARDL aplicados à cointegração (PESARAN; SHIN, 1999; PESARAN et al., 2001). Tal método tem vantagens em comparação aos testes de cointegração em variáveis não estacionárias e aos modelos de Vetores Autorregressivos (VAR). Dentre elas, poder ser aplicado em modelos com variáveis com diferentes ordens de integração, sejam estacionárias em nível $\mathrm{I}(0)$ ou integradas em primeira ordem $\mathrm{I}(1)$, desde que não sejam integradas de segunda ordem I(2). Além disso, é mais eficiente para captar relações de longo prazo em amostras pequenas - o que se aplica a este estudo - e é possível determinar o número ótimo de defasagens para cada variável do modelo por intermédio de um critério de seleção previamente escolhido.

A metodologia ARDL consiste em verificar se existe cointegração entre um conjunto de variáveis por meio de regressões por Mínimos Quadrados Ordinários (MQO) com defasagens das variáveis dependente e explicativas. Confirmada a existência de vetores de longo prazo entre as variáveis de interesse, estimam-se os coeficientes de longo e curto prazos dos modelos, bem como a velocidade de ajustamento ao equilíbrio de longo prazo (PESARAN; SHIN, 1999; PESARAN et al., 2001). Para isso, o modelo ARDL é estimado na forma de vetores de correção de erros (ARDL-ECM), podendo ser especificado de acordo com a equação (1).

$\Delta y_{t}=\alpha_{0}+\delta_{i} y_{t-1}+\delta_{i} x_{t-1}+\sum_{i=0}^{n} \phi_{i} \Delta y_{t-i}+\sum_{i=0}^{n} \phi_{i} \Delta x_{t-i}+\varepsilon_{t}$

sendo: $\Delta$ a primeira diferença; $y_{t}$ a variável dependente; $\alpha_{0}$ a constante; $\delta_{i}$, com $i=1,2, \ldots, n$, os parâmetros de longo prazo; $x_{t-1}$ o vetor de variáveis explicativas; $\phi_{i}(i=1,2, \ldots, n)$ os parâmetros de curto prazo; e $\varepsilon_{t}$ o termo de erro.

Para efetivar a análise, após as estimações por MQO, utiliza-se o teste Wald (estatística-F) para a verificação da significância conjunta dos parâmetros de longo prazo. Entretanto, sob a hipótese nula de não existência de cointegração, os valores críticos do teste Wald não possuem uma distribuição assintótica padrão para qualquer ordem de integração dos regressores. Por isso, Pesaran et al. (2001) sugerem uma banda de valores críticos, na qual o nível inferior é calculado com a hipótese de que todas as variáveis do modelo ARDL são I(0) e a banda superior é mensurada considerando a hipótese de que todas as variáveis são I(1).

Definida a banda de valores críticos, é comparada a ela a estatística-F do teste Wald. A hipótese nula é a de não existência de vetores de cointegração. Assim, se a estatística-F ficar abaixo da banda inferior de valores críticos, a hipótese nula não é rejeitada; ou seja, não há cointegração. Se a estatística-F for maior do que a banda superior de valores críticos, a hipótese nula é rejeitada, ou seja, há cointegração. Por fim, se a estatística-F do teste Wald ficar dentro do intervalo de valores críticos, os resultados são inconclusivos.

Previamente à estimação dos modelos ARDL, deve-se verificar se as variáveis utilizadas não são integradas de segunda ordem I(2). Tal verificação é realizada por meio da aplicação dos testes tradicionais de raiz unitária. Ademais, testes de diagnóstico devem ser realizados para avaliar a autocorrelação dos resíduos e a estabilidade dos coeficientes dos modelos estimados.

O Quadro 1 apresenta as variáveis (dependentes e explicativas de interesse e de controle) consideradas nos modelos estimados neste estudo. Tais variáveis consideram dados brasileiros de 1985 a $2014^{1}$ e todas são empregadas em transformações logarítmicas (logaritmo natural). Na Tabela A.1 do Apêndice são apresentadas estatísticas de todas as variáveis aqui utilizadas.

Como variáveis dependentes, são utilizadas as proxies Gini e Pobreza para sinalizarem a desigualdade de renda e a pobreza, respectivamente. Assim, como proxy para a desigualdade, adota-se a medida mais utilizada pela literatura sobre o tema, principalmente em avaliações da CK (ANAND; KANBUR, 1993; DEUTSCH; SILVER, 2001). Já como proxy para a pobreza, é utilizada uma das medidas mais tradicionais: a proporção de pobres baseada em necessidades calóricas das pessoas - a partir da qual é traçada uma linha de pobreza. Assim, considerando aspectos já comentados, é adotada uma medida de pobreza absoluta (CRESPO; GUROVITZ, 2002; KAGEYAMA; HOFFMANN, 2006). Portanto, as estimações aqui realizadas seguem a proposta de avaliação da hipótese do crescimento pró-pobre investigando a dinâmica dos mais pobres independentemente dos mais ricos (RAVALLION, CHEN, 2003; RAVALLION, 2004).

\footnotetext{
${ }^{1}$ Período definido devido à disponibilidade dos dados necessários para a construção das variáveis consideradas.
} 
Quadro 1 - Variáveis utilizadas nos modelos

\begin{tabular}{|c|c|c|}
\hline Variáveis & Descrições & Fontes \\
\hline \multicolumn{3}{|c|}{ Variáveis Dependentes } \\
\hline Gini & $\begin{array}{l}\text { Proxy para a desigualdade de renda dada pelo coeficiente de Gini da renda } \\
\text { domiciliar per capita (variação entre } 0 \text { a } 1 \text { ) }\end{array}$ & Banco Mundial \\
\hline Pobreza & $\begin{array}{l}\text { Proxy para a pobreza dada pela proporção de pobres (linha de pobreza baseada } \\
\text { em necessidades calóricas) em relação à população total }(\%)\end{array}$ & PNAD/IBGE \\
\hline \multicolumn{3}{|c|}{ Variáveis Explicativas de Interesse } \\
\hline$P I B$ & PIB per capita (US\$ constantes de 2010) & $\begin{array}{l}\text { Banco } \\
\text { Mundial }\end{array}$ \\
\hline Indústria & Participação do emprego formal da indústria no emprego formal total $(\%)$ & RAIS \\
\hline \multicolumn{3}{|c|}{ Variáveis Explicativas de Controle } \\
\hline Salário & Salário mínimo real (Índice $2010=100$ ) & IPEA \\
\hline Educação & $\begin{array}{l}\text { Proxy para gastos com educação dada pela despesa per capita da União com } \\
\text { educação e cultura ( } \mathrm{R} \$ \text { constantes de } 2010)\end{array}$ & Tesouro Nacional \\
\hline
\end{tabular}

IBGE - Instituto Brasileiro de Geografia e Estatística; IPEA - Instituto de Pesquisa Econômica Aplicada; PNAD - Pesquisa Nacional por Amostra de Domicílios; RAIS - Relatório Anual de Informações Sociais.

As variáveis explicativas de interesse para este estudo são: PIB e Indústria. A primeira é o Produto Interno Bruto (PIB) per capita (em logaritmo), pela qual são averiguadas as relações do crescimento econômico com a desigualdade e a pobreza. Trata-se da medida mais utilizada por trabalhos que investigam empiricamente as hipóteses da CK e do crescimento pró-pobre.

A segunda variável é a participação da indústria no emprego, tendo o intuito de captar possíveis relações da indústria com a desigualdade e a pobreza. Esta é uma das medidas mais tradicionais de (des)industrialização (ROWTHORN; RAMASWAMY, 1997). Vale ressalvar que é aqui reconhecida a crítica de Tregenna (2009) quanto ao uso somente do emprego formal para caracterizar tal processo. Contudo, opta-se por tal medida por ser plausível supor que é via emprego o canal do possível efeito da indústria sobre as variáveis dependentes aqui analisadas.

Além disso, a participação industrial no emprego também é justificável por ser advogada na literatura em avaliações de impactos da industrialização na desigualdade de renda. Defende-se que tais impactos podem decorrer de efeitos composição e estrutura salarial. O primeiro é a variação da desigualdade gerada por alterações da participação industrial na economia; já o segundo é a variação da desigualdade em decorrência de mudanças no nível de remuneração na indústria (SOARES, 2006; HOFFMANN; NEY, 2008). Nesse sentido, para posteriormente fundamentar as análises dos resultados, vale resgatar outra evidência já comentada: a indústria, em comparação aos outros grandes setores, concentra menos renda no Brasil e possui nível de renda relativamente maior (HOFFMANN, 2011; OLIVEIRA; SILVEIRA NETO, 2016).

As variáveis de controle são: Salário e Educação. A primeira representa o salário mínimo (em índice), que controla possíveis impactos de um dos fatores mais associados na literatura a variações da desigualdade de renda e da pobreza no Brasil. Pode-se destacar como exemplos: i) o aumento da desigualdade e pobreza nos anos 1980, quando políticas de congelamento de salários foram adotadas; e ii) a redução da desigualdade e da pobreza nos anos 2000, quando ocorreram políticas de valorização real do salário mínimo. As décadas de 1980 e 2000, ao menos parcialmente, são contempladas no período analisado neste estudo (1985 a 2014). Os trabalhos sugerem, no geral, relações negativas, ou seja, aumentos (reduções) do salário mínimo provocariam reduções (aumentos) da desigualdade e da pobreza (BARROS et al., 2006).

O segundo controle é uma proxy para a formação de capital humano, representando os gastos públicos com educação e buscando controlar efeitos desta dimensão na desigualdade e na pobreza. A discussão sobre justificativas para a CK fundamenta tal controle. Ademais, vale apontar que: i) a variável é amplamente utilizada em trabalhos relativos à Teoria do Capital Humano ou baseados em Mincer (1974); ii) a educação teve papel central em debates sobre a dinâmica da desigualdade e da pobreza no Brasil, como na já comentada "controvérsia de 70" (LANGONI, 1973, GANDRA, 2005); e iii) as políticas educacionais são apontadas como uma das causas da queda da desigualdade e pobreza no país nos anos 2000 (BARROS et al., 2006).

Realizados tais apontamentos, deve-se destacar que são estimadas duas especificações de modelos ARDL aplicados à cointegração para cada uma das duas variáveis dependentes. Na primeira especificação, conforme as equações (2) e (3) - modelos restritos -, são consideradas apenas as variáveis dependentes e as explicativas de maior interesse para o estudo. O modelo 1 - equação (2) - estima as relações de curto e longo prazos entre a desigualdade de renda (Gini), o crescimento econômico $(P I B)$ e a participação industrial no emprego (Indústria). O modelo 2 - equação (3) - estima as relações de curto e longo prazos entre a pobreza (Pobreza), o crescimento econômico (PIB) e a participação industrial no emprego (Indústria). 
Modelo 1:

$\Delta$ Gini $_{t}=\alpha_{0}+\delta_{1}$ Gini $_{t-1}+\delta_{2}$ PIB $_{t-1}+\delta_{3}$ Indústria $_{t-1}+\sum_{i=0}^{n} \phi_{1} \Delta$ Gini $_{t-1}+\sum_{i=0}^{m} \phi_{2} \Delta P I B_{t-1}+$ $\sum_{i=0}^{p} \phi_{3} \Delta$ Indústria ${ }_{t-1}+\varepsilon_{t}$

Modelo 2:

$\Delta$ Pobreza $_{t}=\alpha_{0}+\delta_{1}$ Pobreza $_{t-1}+\delta_{2}$ PIB $_{t-1}+\delta_{3}$ Indútria $_{t-1}+\sum_{i=0}^{n} \phi_{1} \Delta$ Pobreza $_{t-1}+$ $\sum_{i=0}^{m} \phi_{2} \Delta P I B_{t-1}+\sum_{i=0}^{p} \phi_{3} \Delta$ Indústria ${ }_{t-1}+\varepsilon_{t}$

Assim, as equações (2) e (3) correspondem aos modelos restritos ("mais limpos"), que permitem verificar as relações direta entre as variáveis dependentes e de interesse. Contudo, as outras variáveis determinantes da desigualdade e pobreza (controles) podem afetar em alguma medida os coeficientes estimados. Assim, na segunda especificação, há os controles descritos no Quadro 1 (Salário e Educação). No modelo 3 - equação (4) -, são estimadas as relações para a desigualdade de renda (Gini); já no modelo 4 equação (5) -, para a pobreza (Pobreza).

\section{Modelo 3:}

$\Delta$ Gini $_{t}=\alpha_{0}+\delta_{1}$ Gini $_{t-1}+\delta_{2}$ PIB $_{t-1}+\delta_{3}$ Indústria $_{t-1}+\delta_{4}$ Salário $_{t-1}+\delta_{5}$ Educação $_{t-1}+$ $\sum_{i=0}^{n} \phi_{1} \Delta$ Gini $_{t-1}+\sum_{i=0}^{m} \phi_{2} \Delta P I B_{t-1}+\sum_{i=0}^{p} \phi_{3} \Delta$ Indústria $_{t-1}+\sum_{i=0}^{q} \phi_{4} \Delta$ Salário $_{t-1}+$

$\sum_{i=0}^{r} \phi_{5} \Delta E d u c a c ̧ a ̃ o_{t-1}+\varepsilon_{t}$

Modelo 4:

$\Delta$ Pobreza $_{t}=\alpha_{0}+\delta_{1}$ Pobreza $_{t-1}+\delta_{2}$ PIB $_{t-1}+\delta_{3}$ Indústria $_{t-1}+\delta_{4}$ Salário $_{t-1}+\delta_{5}$ Educação $_{t-1}+$ $\sum_{i=0}^{n} \phi_{1} \Delta$ Pobreza $_{t-1}+\sum_{i=0}^{m} \phi_{2} \Delta$ PIB $_{t-1}+\sum_{i=0}^{p} \phi_{3} \Delta$ Indústria $_{t-1}+\sum_{i=0}^{q} \phi_{4} \Delta$ Salário $_{t-1}+$ $\sum_{i=0}^{r} \phi_{5} \Delta E d u c a c ̧ a ̃ o_{t-1}+\varepsilon_{t}$

Por último, vale ressaltar que também é considerada uma variável dummy temporal $P B F$ representativa do período de vigência do Programa Bolsa Família (PBF) - igual a 1 a partir de 2003. Tal dummy é considerada por controlar os efeitos de políticas de transferências de renda sobre a desigualdade de renda e a pobreza. $\mathrm{O}$ papel de tais políticas para justificar a CK foi comentado anteriormente. Já Kakwani e Pernia (2000) e Tochetto et al. (2004) destacam a importância de políticas deste tipo como canal de transmissão dos impactos do crescimento econômico nos mais pobres. Barros et al. (2006) advogam políticas de redistribuição de renda, além das educacionais e de valorização salarial, como condicionantes da queda da desigualdade no Brasil nos anos 2010. No contexto do presente estudo, já nas estimações, constatou-se que a inclusão da dummy é necessária para corrigir a instabilidade dos parâmetros do modelo 4.

\section{Resultados e discussões}

Previamente às estimações dos modelos ARDL, deve ser avaliada a ordem de integração das variáveis. Como já apontado, o método pode ser usado em estimações envolvendo variáveis de diferentes ordens de integração, desde que as séries não sejam integradas de segunda ordem [I(2)]. A Tabela 1 resume os resultados dos testes tradicionais de raiz unitária Augmented Dickey-Fuller (ADF), Philips-Perron (PP) e Kwiatkowski-PhillipsSchmidt-Shin (KPSS), os quais indicam que todas as variáveis podem ser consideradas integradas de primeira ordem I(1), o que viabiliza a análise de cointegração e sugere a adequação da metodologia aqui utilizada.

A Tabela 2 apresenta os modelos ARDL aqui selecionados e as defasagens significativas para cada variável nesses modelos, conforme as diversas especificações, sendo utilizadas quatro defasagens e o critério de informação de Akaike (AIC) como base de seleção. São reportados também os resultados dos testes LM de auto correlação dos resíduos, em que é possível detectar a ausência de auto correlação serial em todos os modelos (não rejeição da hipótese nula). 
Tabela 1 - Testes de raiz unitária

\begin{tabular}{ccc|c|cc}
\hline Variáveis / Testes & ADF & PP & KPSS & OI \\
\hline Gini & 0,09 & 1,71 & $0,57^{* *}$ & I $(1)$ \\
Pobreza & 0,47 & $-0,07$ & $0,62^{* *}$ & I $(1)$ \\
PIB & $-0,71$ & $-0,78$ & $0,73^{* *}$ & $\mathrm{I}(1)$ \\
Indústria & $-0,71$ & $-0,73$ & $0,67 * *$ & $\mathrm{I}(1)$ \\
Salário & $-0,38$ & $-0,66$ & 0,24 & $\mathrm{I}(1)$ \\
Educação & $-0,49$ & $-1,52$ & $0,62^{* *}$ & $\mathrm{I}(1)$ \\
\hline
\end{tabular}

Fontes: Banco Mundial, IBGE, IPEA, RAIS e Tesouro Nacional. Elaboração própria a partir de resultados do Eviews 10.

Estimações com constante.

Valores críticos testes ADF e PP: $1 \%(-3,62)$ e $5 \%(-2,94)$.

Valores críticos teste KPSS: $1 \%(0,74)$ e $5 \%(0,46)$.

* e ** rejeição de $\mathrm{H}_{0}$ a $1 \%$ e $5 \%$ de significância, respectivamente.

ADF e PP: $\mathrm{H}_{0}$ : tem raiz unitária.

KPSS: $\mathrm{H}_{0}$ : não tem raiz unitária.

OI: ordem de integração das séries.

Tabela 2 - Estimativas dos modelos ARDL

\begin{tabular}{c|c|c|c}
\hline Modelos & $\begin{array}{c}\text { Modelo ARDL } \\
\text { Selecionado }\end{array}$ & Variáveis Significativas (Defasagens) & $\begin{array}{c}\text { Teste LM } \\
\text { Autocorrelação } \\
\text { (Prob) }\end{array}$ \\
\hline 1 & $(4,4,0)$ & Gini $(-1,-3,-4) ;$ PIB $(0,-2,-4)$; Indústria (0) & 4,0707 \\
$(0,0359)$
\end{tabular}

Fontes: Banco Mundial, IBGE, IPEA, RAIS e Tesouro Nacional. Elaboração própria a partir de resultados do Eviews 10.

$\mathrm{H}_{0}$ : Não há auto correlação serial nos resíduos.

Ainda em termos de diagnóstico, é importante averiguar a estabilidade dos coeficientes dos modelos estimados. Para isso, são realizados os testes de Soma Cumulativa dos Resíduos (CUSUM) e Soma Cumulativa dos Resíduos ao Quadrado (CUSUMSQ), conforme Brown et al. (1975). Nestes testes, a instabilidade nos parâmetros é observada se a soma cumulativa dos resíduos ultrapassa os limites da área das linhas críticas a $5 \%$ de significância estatística, o que sinaliza a influência de quebra estrutural nas estimações. Nas estimações realizadas, os testes CUSUM e CUSUMSQ indicam estabilidade dos parâmetros obtidos para os modelos 1,2 e 3. No modelo 4, a instabilidade verificada é corrigida com a adição da variável dummy $P B F^{2}$.

Após assegurar que as estimativas não apresentam correlação serial e que a dinâmica dos parâmetros é estável, a relação de longo prazo (cointegração) entre as variáveis é examinada com a aplicação dos Testes de Limites (ARDL Bounds Tests), que consiste no teste Wald (F-Test) para verificar a significância conjunta dos parâmetros de longo prazo. Na Tabela 3, são sistematizados os resultados considerando os valores críticos de Pesaran et al. (2001). Os testes indicam que as estatísticas F são maiores do que os valores críticos a 5\%, rejeitando a hipótese de não cointegração em todos os modelos. Ou seja, há relações de longo prazo entre as variáveis.

Tabela 3 - Testes de cointegração ARDL (Bounds Limits)

\begin{tabular}{|c|c|c|c|c|c|c|}
\hline \multirow{3}{*}{ Modelos } & \multirow{3}{*}{ Estatísticas $\mathbf{F}$} & \multicolumn{4}{|c|}{ Valores Críticos } & \multirow{3}{*}{$\begin{array}{c}\text { Existe cointegração } \\
\text { de longo prazo? }\end{array}$} \\
\hline & & \multicolumn{2}{|c|}{$\mathrm{I}(0)$ Bound } & \multicolumn{2}{|c|}{ I(1) Bound } & \\
\hline & & $10 \%$ & $5 \%$ & $10 \%$ & $5 \%$ & \\
\hline 1 & 8,66 & 2,63 & 3,10 & 3,35 & 3,87 & Sim \\
\hline 2 & 7,79 & 2,63 & 3,10 & 3,35 & 3,87 & Sim \\
\hline 3 & 22,52 & 2,20 & 2,56 & 3,09 & 3,49 & Sim \\
\hline 4 & 12,42 & 2,20 & 2,56 & 3,09 & 3,49 & Sim \\
\hline
\end{tabular}

Fontes: Banco Mundial, IBGE, IPEA, RAIS e Tesouro Nacional. Elaboração própria a partir de resultados do Eviews 10. $\mathrm{H}_{0}$ : não há relação de longo prazo.

\footnotetext{
${ }^{2}$ Os gráficos dos testes CUSUM e CUSUMSQ são apresentados na Figura A.1 a A.4 do Apêndice.
} 
Contudo, é necessário averiguar o impacto de cada variável explicativa sobre as variáveis dependentes em um contexto de longo prazo. Ademais, relações de longo prazo não significam a inexistência de possíveis choques de curto prazo, os quais também devem ser avaliados. A Tabela 4 reporta os coeficientes de cointegração de longo prazo para cada modelo estimado.

Tabela 4 - Coeficientes de longo prazo

\begin{tabular}{c|c|c|c|c}
\hline \multirow{2}{*}{$\begin{array}{l}\text { Modelos / } \\
\text { Variáveis }\end{array}$} & $\mathbf{1}$ & $\mathbf{2}$ & $\mathbf{3}$ & $\mathbf{4}$ \\
\cline { 2 - 5 } & $\begin{array}{c}\text { Coeficientes } \\
\text { (Prob.) }\end{array}$ & $\begin{array}{c}\text { Coeficientes } \\
\text { (Prob.) }\end{array}$ & $\begin{array}{c}\text { Coeficientes } \\
\text { (Prob.) }\end{array}$ & $\begin{array}{c}\text { Coeficientes } \\
\text { (Prob.) }\end{array}$ \\
\hline \multirow{2}{*}{ PIB } & $-0,4474$ & $-3,2168$ & $-0,7708$ & $-4,8507$ \\
& $(0,0000)$ & $(0,0000)$ & $(0,0355)$ & $(0,0001)$ \\
\hline \multirow{2}{*}{ Indústria } & $-0,0406$ & $-0,6965$ & $-0,0296$ & $-0,4474$ \\
& $(0,3519)$ & $(0,0174)$ & $(0,6575)$ & $(0,2608)$ \\
Salário & & & 0,0582 & 0,5556 \\
& & & $(0,2763)$ & $0,1053)$ \\
\hline Educação & & & 0,0723 & 0,1700 \\
& & & $(0,0928)$ & $(0,0735)$ \\
\hline \multirow{2}{*}{ Constante } & 3,6611 & 34,9550 & 5,9516 & 45,8063 \\
& $(0,0000)$ & $(0,0000)$ & $(0,0407)$ & $0,0000)$ \\
\hline
\end{tabular}

Fontes: Banco Mundial, IBGE, IPEA, RAIS e Tesouro Nacional. Elaboração própria a partir de resultados do Eviews 10.

Nos modelos restritos 1 (Desigualdade) e 2 (Pobreza), verifica-se que os coeficientes associados à variável PIB per capita (PIB) são negativos e estatisticamente significantes (a 1\%). Assim, infere-se que o crescimento econômico é relevante para reduzir a desigualdade de renda e pobreza no Brasil no longo prazo, com magnitude maior no segundo modelo, no qual um aumento de $1 \%$ no PIB per capita reduz a pobreza em $3,22 \%$, ao passo em que o efeito sobre a desigualdade é de redução de $0,45 \%$. A participação do emprego industrial no total (Indústria) também apresenta coeficientes negativos, mas com significância (a 5\%) apenas no modelo 2 (Pobreza) - o aumento dessa participação em $1 \%$ diminui a pobreza no longo prazo em $0,7 \%$.

Portanto, os resultados sugerem que o crescimento econômico, no longo prazo, impacta mais a pobreza comparativamente à desigualdade de renda. Resultado similar é sinalizado por Araújo et al. (2013) para os estados brasileiros de 2004 a 2009. Ademais, infere-se que o efeito da participação industrial (Indústria) segue o do crescimento (menor magnitude), sugerindo que o setor é um canal de redução da pobreza, o que está de acordo com Lipton e Ravallion (1995).

As evidências para os modelos 3 (Desigualdade) e 4 (Pobreza), nos quais há a inclusão das variáveis de controle, assinalam que o efeito do PIB per capita $(P I B)$ se mantém robusto (coeficientes negativos e significativos) em termos de redução da desigualdade $(-0,77 \%)$ e da pobreza $(-4,85 \%)$ no longo prazo, inclusive com maior magnitude em relação aos modelos 1 e 2. Ainda, a participação do emprego industrial (Indústria) mantém o sinal negativo, mas perde significância estatística nos dois modelos, não sendo possível, assim, reforçar com robustez a sua contribuição para explicar a desigualdade de renda e a pobreza no Brasil no longo prazo.

Vale ressalvar que esta alteração pode se relacionar ao argumento de Thorbecke e Jung (1996) de que o setor industrial depende do aumento da qualificação média dos indivíduos para potencializar seu efeito na pobreza. Logo, o controle da educação pode afetar a significância estatística da participação industrial - não sendo possível, então, descartar a possibilidade de que exista sim um efeito desta participação. Deve-se apontar, ainda, que tal dinâmica também se relaciona à formulação de Kuznets (1955), para a qual a industrialização é distribuidora de renda se for acompanhada pelo aumento da qualificação geral dos indivíduos.

Para as variáveis de controle - salário mínimo (Salário) e gastos com educação per capita (Educação) -, os coeficientes apresentam sinais contrários aos que seriam esperados, mas não são estatisticamente significativos, e, portanto, não podem ser interpretados. Assim, pode-se sugerir que as políticas de valorização do salário mínimo e educacionais não possuem relação direta com as variações da pobreza e desigualdade no contexto brasileiro no longo prazo, o que contradiz ao menos parte da literatura. Ressalva-se, contudo, que a aparente ausência de relação não significa a inexistência de efeitos indiretos e importantes. Na verdade, pode ser um indício de que a elevada informalidade no mercado de trabalho e a não universalização e a estrutura desequilibrada do acesso à educação reduzem a capacidade de impacto no longo prazo. Essa possibilidade deve melhor investigada em trabalhos futuros. Nunes et al. (2016), por exemplo, mostra que o Brasil têm gastos percentuais equivalentes a de países desenvolvidos, mas com situações bem inferiores, o que significa que a conversão do gasto em acesso é bem inferior. 
Esses canais foram intensamente investigados a partir da década de 2000 no Brasil, dado o aumento da formalidade do mercado de trabalho brasileiro e do acesso à educação (BARROS et al., 2006). Isso tem elevado, em consequência, o potencial de políticas como a de valorização do salário mínimo sobre a desigualdade e pobreza, não observadas anteriormente. Para o salário mínimo, os resultados sugerem que seus efeitos são conjunturais, impactando na desigualdade somente durante a vigência da política. Para a educação, Silva (2016) mostra evidência similar para o Brasil e para as regiões Centro-Oeste, Norte, Nordeste. Isso implica que os gastos com educação possuem efeitos majoritariamente de curto prazo - como é verificado na Tabela 5 - e que seus efeitos de longo prazo não são significativos em países e regiões em desenvolvimento.

A seguir, são apresentadas as estimações, via mecanismo de correção de erros (ECM), dos ajustamentos de curto prazo dos modelos ARDL. Esta análise é relevante em função dos desequilíbrios de curto prazo serem vistos como um processo de ajustamento ao equilíbrio de longo prazo. Interpreta-se que uma maior velocidade de ajustamento denota que as relações de equilíbrio entre as variáveis retornam ao estado estável mais rápido. Por outro lado, uma menor velocidade de ajustamento significa um retorno mais lento das relações ao estado estável.

A Tabela 5 sistematiza os resultados do mecanismo de correção de erro (ECM) para os modelos ARDL estimados, assim como as variáveis que são estatisticamente significantes para a dinâmica de curto prazo e os respectivos coeficientes. Verifica-se que os sinais do Termo de Correção de Erro $\left(E C M_{t-1}\right)$ são negativos e significativos em todas as estimações e que os valores obtidos são relativamente altos, indicando um rápido ajustamento ao equilíbrio de longo prazo, especialmente no modelo 3 (Desigualdade), com cerca de 95\% dos choques das variáveis no curto prazo corrigidos em um ano, seguido pelos modelos $1(85,05 \%)$ e $2(73,44 \%)$. Já no modelo 4 (Pobreza), o ajuste é um pouco mais lento (56\%), indicando a necessidade de quase dois anos para corrigir os choques das variáveis no curto prazo.

Tabela 5 - Dinâmicas de curto prazo: correção de erros e variáveis significativas

\begin{tabular}{|c|c|c|c|}
\hline Modelos & $\begin{array}{c}\text { ECM(-1) } \\
{[\text { Prob.] }}\end{array}$ & Variáveis Significativas & Coeficientes (Prob.) \\
\hline 1 & $\begin{array}{l}-0,8505 \\
{[0,0000]}\end{array}$ & $\begin{array}{l}\text { DGini(-1) } \\
\text { DGini(-3) } \\
\operatorname{DPIB}(0) \\
\operatorname{DPIB}(-2) \\
\operatorname{DPIB}(-3)\end{array}$ & $\begin{array}{c}0,4559(0,0027) \\
-0,3663(0,0129) \\
-0,2878(0,0057) \\
0,2242(0,0083) \\
0,2759(0,0028)\end{array}$ \\
\hline 2 & $\begin{array}{c}-0,7344 \\
{[0,0000]}\end{array}$ & $\begin{array}{l}\operatorname{DPIB}(0) \\
\operatorname{DPIB}(-3)\end{array}$ & $\begin{array}{r}-1,6127(0,0046) \\
2,2953(0,0001)\end{array}$ \\
\hline 3 & $\begin{array}{l}-0,9468 \\
{[0,0021]}\end{array}$ & $\begin{array}{c}\text { DGini(-3) } \\
\text { DPIB(-1) } \\
\text { DPIB(-2) } \\
\text { DPIB(-3) } \\
\text { DIndústria(0) } \\
\text { DIndústria(-1) } \\
\text { DIndústria(-3) } \\
\text { DSalário(0) } \\
\text { DSalário(-1) } \\
\text { DSalário(-2) } \\
\text { DEducação(-1) } \\
\text { DEducação(-3) }\end{array}$ & $\begin{array}{c}-1,3713(0,0016) \\
0,7729(0,0040) \\
0,7939(0,0034) \\
0,3773(0,0056) \\
-0,3028(0,0104) \\
-0,3007(0,0045) \\
-0,1357(0,0097) \\
-0,1743(0,0038) \\
-0,1122(0,0098) \\
-0,0939(0,0020) \\
-0,0772(0,0024) \\
-0,0158(0,0227) \\
\end{array}$ \\
\hline 4 & $\begin{array}{l}-0,5603 \\
{[0,0000]}\end{array}$ & $\begin{array}{c}\text { DPIB(-1) } \\
\text { DPIB(-2) } \\
\text { DIndústria(0) } \\
\text { DIndústria(-1) } \\
\text { DEducação(-1) }\end{array}$ & $\begin{array}{c}1,4400(0,0009) \\
0,6131(0,0445) \\
-0,9167(0,0017) \\
-0,5895(0,0232) \\
-0,0886(0,0202)\end{array}$ \\
\hline
\end{tabular}

Fontes: Banco Mundial, IBGE, IPEA, RAIS e Tesouro Nacional. Elaboração própria a partir de resultados do Eviews 10.

Nos modelos 1 e 2, observa-se, novamente, a importância do PIB per capita (PIB) para explicar, respectivamente, a desigualdade e a pobreza no Brasil. Embora o efeito inicial da variável (em nível) seja negativo, os coeficientes se mostram positivos nas segunda e terceira defasagens para a Desigualdade (modelo 1) e na terceira para a Pobreza (modelo 2). Assim como em Hichem (2016), tal resultado indica que o crescimento demora certo tempo, em meio aos canais de transmissão, para beneficiar os mais pobres. Assim, as evidências sugerem que o crescimento econômico pode contribuir para agravar a desigualdade e a pobreza no curto prazo, passando a surtir os efeitos benéficos esperados apenas no longo prazo - conforme a Tabela 4 . 
Tal dinâmica está de acordo ao esperado para corroborar a hipótese da CK via modelos ARDL (JALIL, 2015) e para inferir efeitos heterogêneos no tempo do crescimento econômico na pobreza. Assim, a desigualdade de renda e a pobreza tendem a se elevar no curto prazo com o crescimento econômico; porém, no longo prazo, os dois problemas tendem a diminuir com o crescimento. Verifica-se, ainda, que os resultados do PIB se mantêm quando são controladas, nos modelos 3 e 4, as proxies para as políticas salariais (Salário) e educacionais (Educação).

Observa-se, ainda, que a adição dos controles nos modelos 3 e 4, no caso da participação da indústria no emprego (Indústria), cujos coeficientes são negativos e significativos, faz com que ela ganhe relevância para minorar o problema da desigualdade e da pobreza no curto prazo. Resultado semelhante pode ser observado para as proxies de políticas de valorização salarial e educacionais - a última com efeitos significativos somente no modelo 3 (Desigualdade).

Assim, estas políticas são relevantes para a redução, no curto prazo, da desigualdade de renda e da pobreza no Brasil, o que deve ser enfatizado, mesmo com a aparente ausência de efeitos no longo prazo. Por último, pode-se sugerir que o aumento "conjunto" dos coeficientes da participação industrial, do salário mínimo e da educação decorra: i) da indústria empregar parte significativa dos trabalhadores formais brasileiros (SANTOS et al., 2018), que são os mais beneficiados por valorizações do salário mínimo; e ii) dos gastos com educação afetarem, a priori, os empregos relacionados a melhorias e reformas estruturais, como os da indústria e da construção civil. Ademais, essas políticas são correlacionadas com o contexto macroeconômico e político, o que não garante a continuidade de ações positivas ao longo do tempo. Cabe, ainda, o destaque de que a ampliação de $1 \%$ dos gastos com a educação apresenta efeito maior $(0,09 \%)$ para a redução da pobreza relativamente à redução da desigualdade (de $0,02 \%$ a $0,08 \%$ ).

\section{Considerações finais}

O objetivo do presente estudo foi investigar empiricamente possíveis efeitos de curto e longo prazos da (des)industrialização e do crescimento econômico na desigualdade de renda e na pobreza no Brasil. Primeiramente, por meio de uma revisão da literatura, foram justificadas a importância das análises e de opções empíricas. Ademais, foram fundamentadas as hipóteses testadas. Isto porque, além de averiguar como a participação da indústria no emprego relaciona-se à desigualdade de renda e à pobreza, o estudo testou três hipóteses consagradas na literatura.

A primeira hipótese é associada à Curva de Kuznets, no caso, a possibilidade de efeitos heterogêneos do crescimento econômico na desigualdade de renda no curto e no longo prazos, sendo a dinâmica da indústria uma das potenciais explicações - hipótese da economia dual, a segunda testada. A terceira hipótese é a do crescimento pró-pobre. Para isso, foram estimados modelos Autorregressivos de Defasagens Distribuídas (ARDL) aplicados à cointegração, que permitem a identificação de relações de curto e longo prazos entre as variáveis consideradas.

No longo prazo, contatou-se que o crescimento econômico se faz relevante para reduzir a desigualdade de renda e a pobreza no Brasil. Por outro lado, a (des)industrialização (aumento da participação industrial no emprego) não apresentou relação robusta com a desigualdade e a pobreza. Além disso, as evidências encontradas sugeriram que políticas de (des)valorização do salário mínimo e de gastos públicos com educação parecem ser marginais no longo prazo para reduções sustentáveis da pobreza e da desigualdade de renda no contexto brasileiro.

Já no curto prazo, os resultados obtidos indicaram que o crescimento econômico pode contribuir para agravar a desigualdade de renda e a pobreza, passando a ter efeitos negativos (redução) nos problemas sociais aqui considerados apenas no longo prazo. Tal dinâmica sugere como válida, para o Brasil no período aqui analisado, a hipótese associada à Curva de Kuznets de que o crescimento econômico aumenta a desigualdade de renda no curto prazo e a reduz no longo prazo. Ademais, sinaliza efeitos heterogêneos no tempo do crescimento sobre a pobreza.

No caso da participação industrial no emprego formal, foram observados indícios de sua importância mais imediata para a minoração da desigualdade de renda e da pobreza. Assim, a (des)industrialização também possuiria impactos heterogêneos no tempo sobre os problemas sociais aqui considerados. Resultados semelhantes foram constatados no caso das variáveis representativas das políticas educacionais e salariais inseridas nos modelos. Considerando os resultados de longo prazo, pode-se sugerir que estas políticas têm efeitos conjunturais. Cabe ainda o destaque para os gastos com a educação apresentarem um impacto maior na pobreza.

Portanto, as evidências aqui encontradas não refutaram a hipótese da Curva de Kuznets para o Brasil no período analisado. Já a hipótese do crescimento pró-pobre é corroborada apenas no longo prazo. Assim, os 
efeitos do crescimento na pobreza são heterogêneos no tempo. $O$ mesmo foi sinalizado para a (des)industrialização em relação à pobreza e à desigualdade, mas com relações robustas de curto prazo. Assim, além de poder ser setor motor do crescimento e dinamizador da economia, como é defendido na literatura, as evidências obtidas sugerem que a indústria é capaz de contribuir para melhorar a distribuição de renda, pelo menos no curto prazo.

Income Inequality, Poverty, Economic Growth and Industry in Brazil: Short and Long Term Relationships via ARDL Models

Abstract: This paper investigates the short and long run relationships between income inequality, poverty, economic growth and industry participation in employment for Brazil from 1985 to 2014. For this, we estimate Autoregressive Distributed Lag (ARDL) models in order to find out how the industry affects inequality and poverty and to test three traditional hypotheses in the literature: Kuznets Curve, dual economy and pro-poor economic growth. The evidences pointed to heterogeneous effects of growth and industry in poverty and inequality over time, with a social problems reduction explained by economic growth in long run and industry employment in the short run.

Keywords: Income Inequality. Poverty. Economic Growth. Industry. ARDL.

\section{Referências bibliográficas}

ADELMAN, I.; ROBINSON, S. Income distribution and development. In: CHENERY, H.; SRINIVASAN, T. N. (eds.). Handbook of Development Economics. Elsevier Science, 1989.

AHLUWALIA, M. S. Income distribution and development: some stylized facts. The American Economic Review, v.66, n.2, May, 1976.

ALESINA, A.; GLAESER, E. L. Fighting poverty in the U.S. and Europe: a world of difference. Oxford University Press, Oxford, 2004.

ALESINA, A.; RODRIK, D. Distributive politics and economic growth. Quarterly Journal of Economics, v.109, n.2, pp. 465-490, May, 1994.

ANAND, S.; KANBUR, S. M. R. The Kuznets process and the inequality-development relationship. Journal of Development Economics, v.40, n.1, Feb., 1993.

ARAÚJO, J. M.; ALVES, J. A.; BESARRIA, C. N. O impacto dos gastos sociais sobre os indicadores de desigualdade e pobreza nos estados brasileiros no período de 2004 a 2009. Revista de Economia Contemporânea, v.17, n.2, 2013.

BARROS, R. P.; FOGUEL, M. N.; ULYSSEA, G. Desigualdade de renda no Brasil: uma análise da queda recente. IPEA. v. 1. 2006.

BARROS, R. P.; HENRIQUES, R.; MENDONÇA, R. A estabilidade inaceitável: desigualdade e pobreza no Brasil. Textos para Discussão do IPEA, n.800, 2001.

BROWN, R. L.; DURBIN, J.; EVANS, J. M. Techniques for Testing the Constancy of Regression Relationships over Time. Journal of the Royal Statistical Society. Series B (Methodological), pp. 149-192. 1975.

CANO, W. Desequilíbrios regionais e concentração industrial no Brasil - 1930/1970. Tese de LivreDocência, Universidade Estadual de Campinas, 1981.

CARDOSO, J. C.; POCHMANN, M. Raízes da concentração de renda no Brasil: 1930 a 2000. IPEA/CESIT, 2000.

CHRISTIANSEN, L.; DEMERY, L.; KUHL, J. The (evolving) role of agriculture in poverty reduction: an empirical perspective. WIDER Working Paper, n.2010/36, 2010.

CRESPO, A. P. A.; GUROVITZ, E. A pobreza como um fenômeno multidimensional. RAE-eletrônica, v.1, n.2, 
pp. 1-12, 2002.

DAHAN, M.; TSIDDON, D. Demographic transition, the distribution of income and economic growth. Journal of Economic Growth, n.3, pp. 29-52, Mar., 1998.DATT, G.; RAVALLION, M. Farm productivity and rural poverty in India. The Journal of Development Studies, v.34, n.4, pp. 62-85, 1998.

DEUTSCH, J., SILBER, J. The Kuznets curve and the impact of various income sources on the link between inequality and development. Working Papers, n.2001-03, Bar-Ilan University, 2001.

FURTADO, C. Formação econômica do Brasil. Editora Nacional, 7aed., 1967.

GALOR, O.; TSIDDON, D. Income distribution and growth: the Kuznets hypothesis revisited. Economica, v.63, n.250, 1996.

GANDRA, R. O debate sobre a desigualdade de renda no Brasil: da controvérsia dos anos 70 ao pensamento hegemônico nos anos 90. História Econômica \& História de Empresas, v.III, n.1, 2005.

GRADSTEIN, M.; JUSTMAN, M. The democratization of political elites and the decline in inequality in modern economic growth. In: BREZIS, E.; TEMIN, P. (eds.). Elites, Minorities, and Economic Growth. Elsevier, Amsterdam, 1999.

HICHEM, A. Y. A. D. Poverty, inequality and economic growth in Algeria: as ARDL approach. Journal of Social and Economic Statistics, v.5, n.1, Summer, 2016.

HOFFMANN, R. Distribuição da renda agrícola e sua contribuição para a desigualdade de renda no Brasil. Revista de Política Agrícola, v.20, n.2, p. 5-22, 2011.

HOFFMANN, R.; NEY, M. G. A recente queda da desigualdade de renda no Brasil: análise de dados da PNAD, do Censo Demográfico e das Contas Nacionais. Econômica, v.10, n.1, 2008.

JALIL, A. Modeling income inequality and openness in the framework of Kuznets curve: new evidence from China. Economic Modelling, v.29, n.2, pp. 309-315, Mar., 2012.

KAGEYAMA, A.; HOFFMANN, R. Pobreza no Brasil: uma perspectiva multidimensional. Economia e Sociedade, v.15, n.1, v.26, pp. 79-112, 2006.

KAKWANI, N.; PERNIA, E. What is pro-poor growth. Asian Development Review, v.16, n.1, pp. 1-22, 2000. KALDOR, N. Productivity and growth in manufacturing industry: a reply. Economica, v.35, n.140, pp. 385$391,1968$.

KUZNETS, S. Economic growth and income inequality. The American Economic Review, v.45, n.1, 1955.

LANGONI, C. G. Distribuição da renda e desenvolvimento econômico do Brasil: uma reafirmação. Ensaios Econômicos EPGE, n.7, 1973.

LINHARES, F.; FERREIRA, R. T.; IRFFI, G. D.; MACEDO, C. M. B. A hipótese de Kuznets e mudanças na relação entre desigualdade e crescimento de renda no Brasil. Pesquisa e Planejamento Econômico, v.42, n.3, pp. 403-432, 2012.

LIPTON, M.; RAVALLION, M. Poverty and policy. In: Handbook of Development Economics, 1995.

LIST, J. A.; GALLET, C. A. The Kuznets curve: what happens after the inverted-U. Review of Development Economics, v.3, n.2, 1999.

MELLO, J. M. C. O capitalismo tardio: contribuição à revisão crítica da formação e do desenvolvimento da economia brasileira. Brasiliense, São Paulo, 1986.

MINCER, J. Schooling, experience, and earnings. Human Behavior \& Social Institutions. n.2. 1974.

NUNES, A.; ALMEIDA, A. N.; MARQUES, L. R. V.; SOUSA, P. K. R. F. Os gastos públicos no setor de educação no Brasil. Revista de Humanidades, v. 30, n. 2, p. 227-236, 2016.

OLIVEIRA, R.; SILVEIRA NETO, R. M. Estrutura produtiva ou escolaridade? Uma análise dos fatores explicativos da desigualdade de renda entre as regiões Sudeste e Nordeste por quantil para o período entre os anos de 1970 e 2010. Revista Econômica do Nordeste, v.47, n.3, 2016.

PESARAN, M. H.; SHIN, Y. An Autoregressive Distributed-Lag Modelling Approach to Cointegration Analysis. In: Econometrics and Economic Theory in the 20th Century: The Ragnar Frisch Centennial Symposium. Cambridge: Cambridge University Press. 1999.

PESARAN, M. H.; SHIN, Y.; SMITH, R. J. Bounds Testing Approaches to the Analysis of Level Relationships. 
Journal of Applied Economics, vol. 16: 289-326, 2001.

PIKETTY, T. The Kuznets Curve: yesterday and tomorrow. In: BANERJEE, A.; BENABOU, R.; MOOKHERJEE, D. (eds.). Understanding poverty. Oxford Press, 2006.

RAVALLION, M. A comment on Rati Ram's test of the Kuznets hypothesis. Economic Development and Cultural Change, v.46, n.1, pp. 187-190, 1997.

RAVALLION, M. Pro-poor growth: a primer. The World Bank, 2004.

RAVALLION, M.; CHEN, S. Measuring pro-poor growth. Economics Letters, v.78, n.1, pp. 93-99, 2003.

RAVALLION, M.; CHEN, S. China's (uneven) progress against Poverty. Journal of Development Economics, V.82, n.1, pp. 1-42, 2007.

RIBEIRO, L. L.; ARAUJO, J. A.; FEITOSA, D. G. Crescimento pró-pobre: uma análise para os meios urbano e rural no Brasil. Pesquisa e Planejamento Econômico, v.45, n.1, 2015.

ROWTHORN, R.; RAMASWAMY, R. Deindustrialization: causes and implications. Working Paper/97/42. International Monetary Fund. April, 1997.

SANTOS, P. L.; SAIANI, C. C. S.; PEROSA, B. B. Relação entre distribuição dos rendimentos do trabalho e industrialização: evidências para os municípios brasileiros. Anais do III Encontro Nacional de Economia Industrial e Inovação, Uberlândia/MG, 2018.

SEN, A. Sobre conceptos y medidas de pobreza. Comercio Exterior, v.42, n.4, 1992.

SILVA, J. W. Relações e efeitos entre educação, pobreza e crescimento econômico no Brasil e regiões: uma análise entre os anos de 1977 a 2013. Dissertação de Mestrado, Universidade Federal de Pernambuco, 2016.

SOARES, S. S. D. Distribuição de renda no Brasil de 1976 a 2004 com ênfase no período entre 2001 e 2004. Textos para Discussão do IPEA, n.1166, 2006.

SON, H. H. A note on pro-poor growth. Economics Letters, v.82, n.3, pp. 307-314, 2004.

THORBECKE, E.; JUNG, H. S. A multiplier decomposition method to analyze poverty alleviation. Journal of Development Economics, v.48, n.2, pp. 279-300, 1996.

TOCHETTO, D. G. ; RIBEIRO, E. P. ; COMIM, F. V.; PORTO JÚNIOR, S. S. Crescimento pró-pobre no Brasil: uma análise exploratória. Encontro Nacional de Economia, v. 32, 2004.

TREGENNA, F. Characterizing deindustrialization: an analysis of changes in manufacturing employment and output internationally. Cambridge Journal of Economics, v. 33, 2009.

VEGH, C. A.; VULETIN, G.; RIERA-CRICHTON, D.; PUIG, J.; CAMARENA, J. A.; GALEANO, L.; MORANO, L.; VENTURI, $L$. Effects of the business cycle on social indicators in Latin America and the Caribbean: when dreams meet reality. LAC Semiannual Report, World Bank, Washington, DC, 2019.

\section{Apêndice}

Tabela A.1 - Estatísticas descritivas das variáveis consideradas (dependentes e explicativas)

\begin{tabular}{c|c|c|c|c|ccc}
\hline Estatísticas & Gini & Pobreza & PIB & Indústria & Salário & Educação \\
\hline Média & 0,584 & 34,414 & $9.029,958$ & 25,935 & 79,878 & 141,321 \\
Mediana & 0,593 & 35,256 & $8.553,858$ & 24,597 & 81,020 & 118,286 \\
Máximo & 0,636 & 48,734 & $11.912,140$ & 33,593 & 117,730 & 285,363 \\
Mínimo & 0,518 & 13,288 & $7.206,582$ & 20,704 & 48,220 & 40,533 \\
Desvio-Padrão & 0,029 & 9,395 & $1.428,217$ & 3,243 & 21,560 & 69,012 \\
\hline
\end{tabular}

Fontes: Banco Mundial, IBGE, IPEA, RAIS e Tesouro Nacional. Elaboração própria a partir de resultados do Eviews 10. 
Figura A.1 - Modelo 1: testes de estabilidade

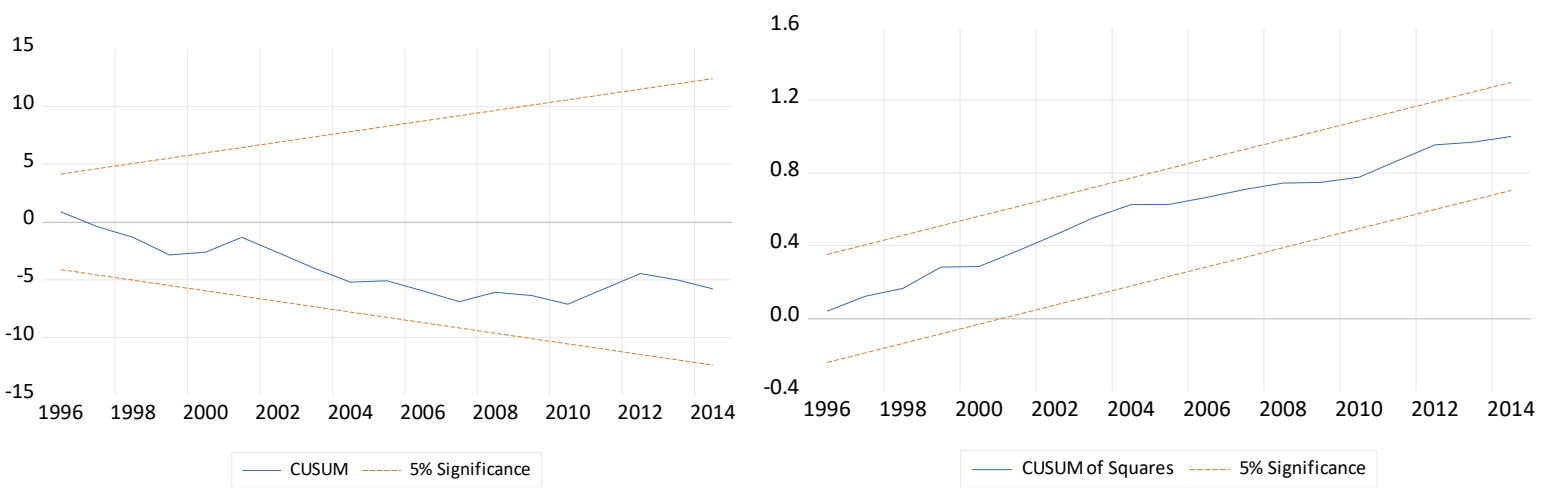

Fontes: Banco Mundial, IBGE, IPEA, RAIS e Tesouro Nacional. Elaboração própria a partir de resultados do Eviews 10.

Figura A.2 - Modelo 2: testes de estabilidade

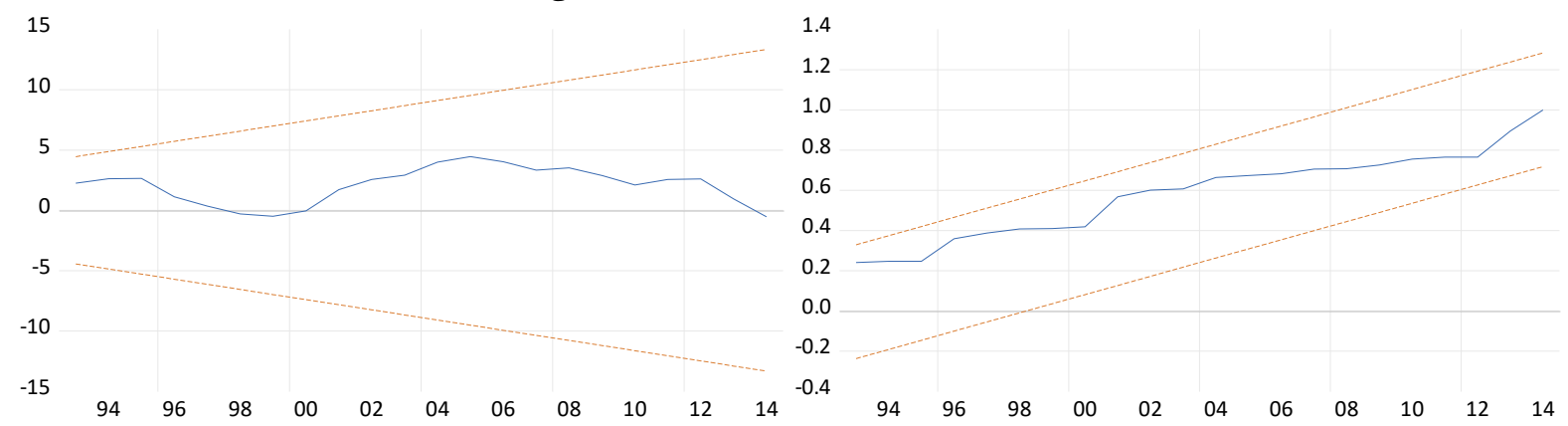

Fontes: Banco Mundial, IBGE, IPEA, RAIS e Tesouro Nacional. Elaboração própria a partir de resultados do Eviews 10.

Figura A.3 - Modelo 3: testes de estabilidade
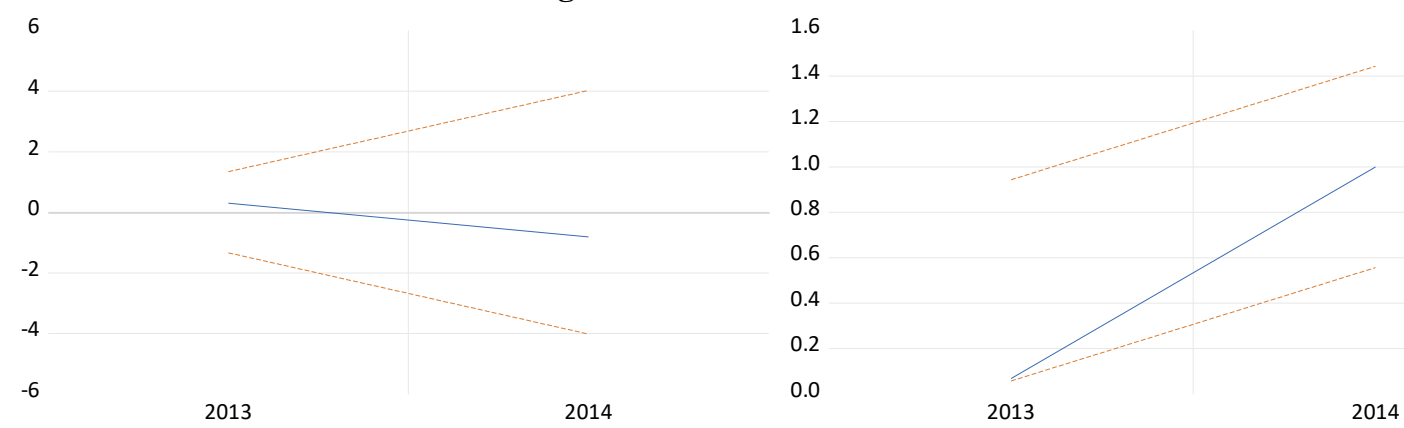

_ CUSUM _-... $5 \%$ Significance

_ CUSUM of Squares _-_-_. $5 \%$ Significance

Fontes: Banco Mundial, IBGE, IPEA, RAIS e Tesouro Nacional. Elaboração própria a partir de resultados do Eviews 10.

Figura A.4 - Modelo 4: testes de estabilidade

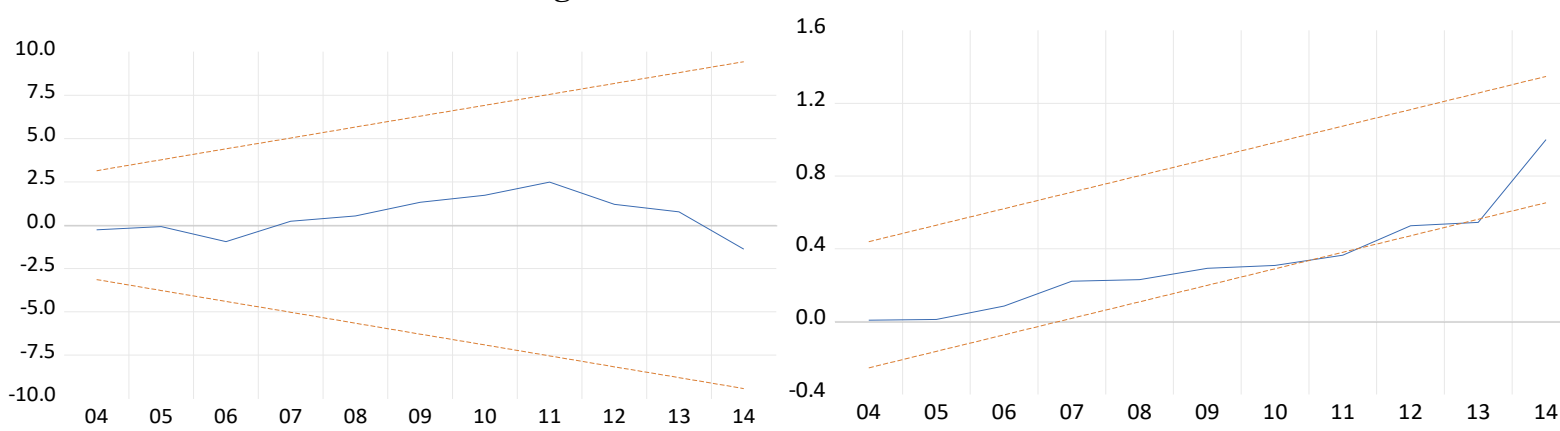

Fontes: Banco Mundial, IBGE, IPEA, RAIS e Tesouro Nacional. Elaboração própria a partir de resultados do Eviews 10. 